DOI: http://dx.doi.org/10.22483/2177-5796.2018v20n1p227-241

\title{
Compartilhar literatura nos anos iniciais do ensino fundamental
}

\author{
Jair Rodrigues Silva \\ Ana Silvia Moço Aparício
}

Resumo: Neste artigo, buscamos desenvolver uma reflexão acerca das possíveis contribuições na perspectiva de compartilhar literatura no cotidiano das escolas de ensino fundamental nos anos iniciais. Com base em referenciais teóricos, que defendem uma concepção ampla de literatura como fruição e alimento, e em dados de entrevistas realizadas com dois professores desse nível de ensino, sobre sua formação literária e prática com o ensino da literatura em suas aulas, evidenciamos que os professores reconhecem o valor da literatura na formação do sujeito, no entanto, não realizam uma prática coerente com essa concepção. A formação inicial do professor, no curso de Pedagogia, bem como a formação continuada para atuar nos anos iniciais do Ensino Fundamental é um aspecto apontado como essencial para que escola possa compartilhar literatura e não promover a inadequada escolarização da literatura como tradicionalmente vem sendo feito na escola.

Palavras-chave: Literatura. Formação docente. Leitura literária.

\section{Sharing literature in the early years of elementary school}

Abstract: In this article we sought to develop a reflection on the possible contributions in the perspective of sharing literature in the routine of elementary schools. Based on theoretical references which support a wide conception of literature for pleasure, and on data from interviews with two elementary school teachers about their literary experience and practice regarding the teaching of literature, we were able to verify that while teachers do acknowledge the value of literature in one's education, they do not have a practice that is coherent to such conception. The early studies of a teacher, in the Pedagogy course, as well as their continuing education to teach elementary students, are considered essential so that schools may share literature, not push for the inadequate literature teaching as it has traditionally been done at schools

Keywords: Literature. Teacher's education. Literary reading. 


\section{Introdução}

Interessa-nos refletir, neste artigo, acerca das possíveis contribuições de compartilhar literatura no cotidiano das escolas de ensino fundamental nos anos iniciais, a partir de referenciais teóricos e dados de entrevistas realizadas com dois professores desse nível de ensino. É nosso objetivo propor e discutir o termo "compartilhar" em vez de ensinar ou trabalhar a literatura; isto se deve ao fato de concebermos a leitura literária sob uma perspectiva de leitura fruição ao invés de burocratizá-la, escolarizá-la como afirma Soares (2011).

Nesta perspectiva, a literatura no processo de aprendizagem remete ao pensamento de Freire (1996), em que o processo de ensino e aprendizado não pode se dar fora da boniteza e da alegria. "A alegria não chega apenas no encontro do achado, mas faz parte do processo da busca. E ensinar e aprender não pode dar-se fora da boniteza e da alegria” (FREIRE, 1996, p. 142). Nesse sentido, a literatura representa a boniteza, a alegria do encontro com o novo, do inesperado no cotidiano escolar. Daí vem uma das razões que justifica a expressão “compartilhar”. Buscando desenvolver uma reflexão nessa perspectiva, discutimos a seguir, mais detalhadamente, o conceito de "compartilhar literatura". Por fim, apresentamos e analisamos dados de entrevistas realizadas com dois professores dos anos iniciais do Ensino Fundamental sobre a formação e prática literária no processo de ensino aprendizagem dos alunos.

\section{Compartilhar literatura: caminhos e possibilidades}

A utilização do termo "compartilhar literatura" em razão de ensinar ou trabalhar literatura no processo de ensino aprendizagem justifica nossa posição quanto ao que acreditamos ser o lugar da leitura literária no cotidiano das salas de aula. Longe de ser uma obrigação presente no currículo, ou algo para passar o tempo da aula ou ainda formatada para exemplificar o uso das classes gramaticais e interpretação textual, a leitura literária é por nós pensada como uma forma estética e artística com vistas a contribuir com a formação de leitores efetivos que possam manter o hábito de leitura ao longo de suas vidas.

A literatura, em nossa visão, está ligada à experiência artística, como afirma Todorov (2010) ao escrever o que pode a literatura: 
A literatura pode muito. Ela pode nos estender a mão quando estamos deprimidos, nos tornar ainda mais próximos dos outros seres humanos que nos cercam, nos fazer compreender melhor e mundo e nos ajudar a viver. Não que ela seja, antes de tudo, uma técnica de cuidados para com a alma; porém, revelação do mundo, ela pode também, em seu percurso nos transformar a cada um de nós a partir de dentro (p. 76).

O pensamento de Todorov (2010) acerca da literatura corresponde a nossa proposta de compartilhar literatura em sala de aula. Para tanto, pensemos inicialmente sobre a palavra “compartilhar". Segundo o Cunha (1997) a palavra "compartilhar" vem de "partir” que significa dividir em partes. Segundo o dicionário Michaelis (2017), compartilhar significa: 1 - Ter ou tomar parte em. 2 - Partilhar com alguém.

Dessa forma, na expressão "compartilhar", a literatura ganha a dimensão de envolver, de participar o aluno na experiência literária, trazendo no bojo as esperadas contribuições que um trabalho significativo com práticas de leitura literária pode agregar ao processo de ensino aprendizagem. Compreendendo assim, compartilhar literatura em sala de aula é um processo artístico, compartilhar seria mais do que apenas ler, ou entregar um livro para que o aluno o faça. Retomamos Freire (1996) quando o assunto é ler:

Não se lê criticamente, como se fazê-lo fosse a mesma coisa que comprar mercadoria por atacado. Ler vinte livros, trinta livros. A leitura verdadeira me compromete de imediato com o texto que a mim se dá e a que me dou e de cuja compreensão fundamental me vou tornando também sujeito (p. 27).

Compartilhar literatura é, portanto, participar a si e ao outro, como digo durante minhas apresentações de narração de histórias: Narrar é ir ao outro. Mais do que ler, a experiência literária pressupõe uma leitura não mecânica e vazia de sentido, tanto para quem lê como para quem ouve. Compartilhar literatura requer envolvimento, prazer e fruição, daí sua ideia de boniteza e alegria no cotidiano da sala de aula.

Quando compartilhamos literatura, temos a possibilidade de desenvolver o senso crítico e a criatividade. Narrar/contar histórias se configura numa ação de compartilhar literatura, na medida em que este ato pressupõe literalmente ir ao outro. Encontramos um exemplo disso em Machado (2004), cuja perspectiva acerca da arte de contar histórias aproxima-se do que propomos ser o compartilhar literatura:

Fico pensando em alguém que resolve dedicar algumas horas de sua vida lendo histórias para uma criança desconhecida, deitada numa cama de hospital. Não é o medo que une essas duas pessoas nesse instante. Ambas transitam, cada uma pela sua própria história, dentro do conto. Não se trata de negar ou fugir da realidade, do medo ou da impotência. 
Experimentam a si mesma em outras possibilidades de existir, além do medo (MACHADO, 2004, p. 15).

Acreditamos que narrar histórias é também uma forma de compartilhar a literatura. De acordo com nossa experiência em sala de aula, não foram poucas as vezes em que narrar histórias transformou um dia comum numa experiência atenta com olhos atentos e um significativo silêncio que muito tinha a dizer.

Acreditamos que literatura, no sentido que apresentamos aqui, não se ensina. Assim como não se ensina a sentir alegria, medo ou descobertas que a literatura nos proporciona. A experiência compartilhada a partir das histórias orais também é um tema abordado por Benjamin (1994, p. 198): “A experiência que passa de pessoa a pessoa é a fonte a que recorreram todos os narradores. E, entre as narrativas escritas, as melhores são as que menos se distinguem das histórias orais contadas pelos inúmeros narradores anônimos”.

As histórias orais, quando compartilhadas, pressupõem o contato com o outro. É nesse ato que o compartilhar está presente. Não se atendo somente ao ato de narrar uma história da tradição oral, Benjamin (1994) fala sobre a experiência da leitura solitária de um leitor de romance, que, mesmo em ato solitário, interage com a narrativa, emprestando a esta suas emoções, experiência e conhecimento de mundo.

Quem escuta uma história está em companhia do narrador e mesmo quem a lê partilha dessa companhia. Mas o leitor de um romance é solitário. Mais solitário que qualquer outro leitor (pois mesmo quem lê um poema está disposto a declamá-lo em voz alta para um ouvinte ocasional). Nessa solidão, o leitor do romance se apodera ciosamente da matéria de sua leitura. Quer transformá-la em coisa sua, devorá-la, de certo modo. Sim, ele destrói, devora a substância lida, como o fogo devora lenha na lareira. A tensão que atravessa o romance se assemelha muito à corrente de ar que alimenta e reanima a chama (BENJAMIN, 1994, p. 213).

Em síntese, literatura pressupõe o contato com nossos pares. Seja ela compartilhada em narração de histórias, declamação de poemas ou numa leitura "solitária", estamos participando, repartindo. Deve-se converter numa experiência significativa por ser compartilhada entre professores e alunos como iguais.

\section{Os dados da pesquisa}

A seguir, vamos analisar o que dizem dois professores participantes de nossa pesquisa que atuam nos anos iniciais do Ensino Fundamental, a respeito do papel da literatura no processo 
de ensino aprendizagem.

Trata-se de uma professora e de um professor que atuam em uma escola de tempo integral da rede municipal na região do Grande ABC paulista. Para preservar suas identidades eles serão denominados aqui, aleatoriamente, com nomes de personagens de obras clássicas da literatura. De forma que a professora será denominada como Capitu, e o professor como Hamlet. Apresento a seguir o perfil pessoal, o perfil de leitor e o perfil profissional dos dois professores entrevistados.

\section{Capitu: a importância da formação continuada}

Capitu tem 42 anos, formou-se no Magistério em 1994 e em Pedagogia em 2002 e atua como docente desde 1997 na mesma rede municipal. Leciona há 10 anos na atual escola e, no momento, atua em uma turma de $3^{\circ}$ ano, com carga horária de 50 horas aulas por semana, 25 horas aulas com as disciplinas de Língua Portuguesa, História, Ciências e Geografia no período da manhã e à tarde mais 25 horas aulas com as oficinas de Iniciação Científica, Robótica, Experiências Matemáticas, Produção de Texto e Orientação de Estudos. Quanto à sua percepção sobre a formação acadêmica recebida, a professora atribui maior valor à prática e à formação continuada oferecida pela rede em que atua, do que à formação na graduação, como podemos observar no trecho a seguir.

Eu aprendi muito na prática. Aprendi no dia a dia, porque na formação, eu senti muita falta. Eu trabalhava de dia e estudava à noite. Então, não tive um aproveitamento como deveria ter. Não teve o cuidado, a estimulação. Eram apostilas e muita teoria. Quando entrei na rede [em 1997, que teve vários cursos de formação para professor, de formação continuada, eu comecei a encarar de outra forma. Eu achei que foi bem válida essa formação. Pena que não tem mais.

A professora Capitu também afirma que não houve contribuições do curso de Pedagogia para a prática da leitura literária, embora considere essa formação muito importante.

Pelo que tenho conversado e pela minha formação eu acho que não. Que eles precisam se dedicar mais a essa área de formar leitores. Até porque nós vamos formar leitores em sala de aula. Há uma necessidade muito grande do curso de Pedagogia reformular isso.

Quanto à sua trajetória de leitora, embora hoje Capitu valorize muito a leitura, ela não teve contato com livros de literatura em sua infância, seja na família ou nos anos iniciais da escola, como relata no trecho abaixo. 
SILVA, Jair Rodrigues; APARÍCIO, Ana Silvia Moço. Compartilhar literatura nos anos iniciais do ensino fundamental.

Em casa? Bom, infelizmente minha mãe não era alfabetizada. Então eu não tive contato com livros de literatura quando eu era criança. Eu vejo pelo meu filho. Ele tem tantos livros e os lê [...]. Realmente, isso fez diferença na minha vida. Queria ter tido mais [...]. Acho que tinha um tio ou uma tia que incentivava, mesmo assim ela não me deu nenhum livro para eu ler. [...]. Não me lembro de nenhuma indicação de livro da professora e nem de ela ler livros para nós. Era uma sala de aula bem tradicional, com 42 alunos levados de forma bem rígida pela professora.

Somente nos anos finais do Ensino Fundamental, a professora Capitu se lembra de ter tido experiência com a leitura literária na escola, porém não muito positiva, o que acabou levando a professora a fazer outras escolhas, certamente influenciada por aspectos religiosos. O relato a seguir evidencia essas experiências.

Depois, no fundamental 2, eu lia os livros para fazer as provas e na adolescência eu tinha uma indicação de livros de romance que eu ia na biblioteca e pegava emprestado para eu ler, não havia dinheiro para comprar livros. Então eu lia o Sidney Sheldon. Eu lia também muita literatura evangélica, que falava de missões e de como as pessoas sofriam para passar a mensagem [...]. Eu sempre lia muito esse tipo de literatura.

Sobre a obrigação de ler livros para realizar as avaliações, a professora Capitu considera uma prática escolar que não contribui para despertar o prazer e o hábito de ler, apontando inclusive a leitura obrigatória pelo professor como uma prática recorrente na escola.

Porque era pra fazer prova então não era muito bom. Eu me sentia forçada. Se eu tivesse o hábito de ler, com certeza não seria nada maçante. Mas como eu não tive ninguém que me incentivasse [...]. Eu não me lembro os nomes dos livros que li [...]. Pelo que eu percebo, salvo alguns professores, a maioria dos professores lê para seus alunos por obrigação. Eu vejo que é muito pela família que passa o incentivo, mas um bom professor pode incentivar os alunos.

A concepção da professora Capitu sobre leitura significativa está relacionada à aplicabilidade na vida do leitor, conforme ela relata a seguir.

Para mim uma leitura é significativa quando eu consigo aplicar ela para minha vida. Quando ela faz sentido e eu consigo tirar uma lição dela. Quando uma leitura é assim, é porque ela é significativa para mim.

Os hábitos atuais de leitura de Capitu continuam sendo bastante influenciados por motivações religiosas, assim como já ocorria em sua adolescência. Inclusive, a professora reconhece que não é leitora de texto literário, e assume que somente tem o contato com a literatura no contexto escolar. Nos trechos a seguir, Capitu deixa isso bem claro.

Eu leio livros que me foram indicados, às vezes até indicados por um programa de rádio por exemplo. Foi assim que li Rubem Alves. Eu leio muito literatura religiosa. Até porque meu marido é teólogo e por isso eu tenho muitos livros dessa área em minha casa. Para ser um leitor literário é preciso estar em constante contato com os livros literários e minhas preferências de leitura são outras. Só leio literatura quando leio 
SILVA, Jair Rodrigues; APARÍCIO, Ana Silvia Moço. Compartilhar literatura nos anos iniciais do ensino fundamental.

para os alunos ou quando preciso conhecer um livro antes de ler para eles. Para mim, ler por fruição é quando uma leitura faz sentido e quando consigo aplicá-la para minha vida. Diariamente eu faço a leitura da Bíblia.

Quanto a aspectos do perfil profissional da professora Capitu, é possível perceber que seu trabalho com a literatura em sala de aula é incentivado pelas ações de formação e, quando isso não ocorre, seu trabalho perde força, ainda que o considere essencial. Vejamos o relato a seguir sobre o tempo que Capitu dedica à leitura literária em suas aulas.

Eu dedico umas duas aulas por semana. Às vezes uma, às vezes duas. Antigamente eu lia todos os dias ao menos 20 minutos, eram leituras por capítulos, porque era uma proposta da nossa rede, da nossa formação continuada. Mas infelizmente isso foi se perdendo. Hoje eu leio à tarde, algumas vezes por semana, uns 30 minutos. Mas eu acho que isso deveria ser uma prática diária.

Sobre os critérios utilizados para a escolha de livros literários para leitura, a professora Capitu explicou que leva em consideração a faixa etária de sua turma e se o livro pode estar atrelado a algum conteúdo trabalhado no currículo, como evidencia seu relato a seguir.

Considero em primeiro lugar a faixa etária da minha turma e os livros que parecem trazer histórias mais divertidas, tais como Os Pestes. Penso também se é possível envolver a leitura com algum conteúdo. Exemplo: um livro que fale sobre diário, quando estamos envolvidos com este gênero em Língua Portuguesa. A indicação de professores parceiros e da coordenação também levo em consideração para a escolha dos livros para ler em sala de aula.

A professora Capitu não considera que os livros didáticos abordam a literatura de forma adequada, conforme evidencia o seu relato.

Acho que os livros mostram a literatura com trechos curtos ou adaptações que podem tirar o sentido das histórias. Seria melhor que apresentassem as obras com mais cuidado, inclusive abordando a biografia do autor. Os livros didáticos são pobres nesse sentido. Outra coisa que os livros deveriam mostrar mais são outros livros do autor, como também recomendações de leitura. São trechos curtos demais e não se tem a ideia de toda a obra.

Contudo, ainda que não se considere uma leitora de literatura, a professora acredita que a leitura literária pode contribuir em muito para a formação de alunos leitores, atribuindo à literatura o importante papel humanizador. Nos trechos abaixo, a professora relembra um caso ocorrido em sala de aula que demonstrou como a leitura foi significativa para os alunos.

Como eu sempre digo: Ler é importante porque abre caminhos. Porque te abre novos horizontes. É importante para conhecer novas situações. Conhecer por exemplo a questão da economia, conhecer uma determinada situação. É importante porque você cresce com isso. E deixar de ficar pensando pequeno, como dizem as pessoas. E começar a pensar em outras situações, às vezes de sua vida mesmo, ou da sociedade [...]. Teve uma leitura que a gente fez, que eles gostaram muito e interagiram bastante. Colocaram suas opiniões e crianças que quase nunca falavam, colocaram sua opinião. Foi bem válido. Por isso a literatura é importante para formar leitores. A partir do gosto de ler é que se forma um bom leitor.

Quaestio, Sorocaba, SP, v. 20, n. 1, p. 227-241, abr. 2018 
SILVA, Jair Rodrigues; APARÍCIO, Ana Silvia Moço. Compartilhar literatura nos anos iniciais do ensino fundamental.

Por isso, para Capitu, um bom livro de literatura, para ser compartilhado na escola, tem de ser um livro motivador e também prender a atenção dos alunos por sua história.

Para ser um bom livro para leitura em sala de aula, o livro tem que ser interessante, que tenha uma boa história. Que seja divertido e que sua história prenda os alunos até o fim. Isso aconteceu com o livro dos Pestes que prendeu a atenção dos alunos até o fim. Todos queriam saber o que aconteceu com aqueles velhos que odiavam crianças e comiam empadão de passarinho. Foi muito divertido para eles. Foi uma leitura realizada em capítulos.

Mas, para isso, a professora Capitu reconhece a importância da formação do professor para a formação de bons leitores. O trecho a seguir revela essa consciência da professora.

Incentivar e ser um modelo de leitor para esse aluno. Eles [os professores] tentam, por causa da formação continuada, buscar. Nós não podemos jogar nossa experiência na vida das crianças. Se nós não tivemos, eles também não terão. A gente tem que ter essa consciência de que eles precisam ter. Então a gente busca formação fora, para ver se consegue resgatar isso. O professor precisa ser um modelo de leitor. Como quando eu digo que é momento de leitura e cada aluno pega um livro para ler e o professor não lê, não é bom. Precisa ser um modelo de leitor.

Mais uma vez Capitu comenta sobre a importância da formação continuada do professor para o trabalho com a literatura na sala de aula dos anos inicias. Para isso, destaca a responsabilidade da escola e da rede, como apontado no trecho a seguir.

Quando eu entrei na rede tinha. Agora, de uns três anos para cá não tem tido, infelizmente. Eles não podem pensar que todos os professores estudaram em escolas maravilhosas, tiveram famílias que ajudaram. Não são todos assim. Cada um tem sua formação geral. Eles têm que pensar nos alunos, nas futuras gerações. E preparar melhor os professores.

Em síntese, podemos dizer que, a partir dos dados obtidos na entrevista, a professora Capitu demonstra considerar a importância da literatura para a formação de leitor, e que muito desse processo passa pelo trabalho do professor. Capitu afirmou não ter tido uma formação suficiente em relação à leitura literária quando estava cursando Pedagogia, mas que é importante o professor passar por formações que contemplem uma formação literária que possa preparar o professor para as práticas de leitura em sala de aula. Outro fator importante é a valorização que a professora destaca para a literatura em suas falas e ainda que não tenha tido, segundo suas palavras, uma formação literária adequada, ela segue trabalhando, às vezes com mais ou menos intensidade, a literatura em suas práticas de leitura em sala de aula. E que para ela seria importante passar por formações que incentivassem a leitura literária e a formação de leitores. 


\section{Hamlet: ler é ter autonomia}

Hamlet tem 31 anos, formou-se no Magistério em 2004 e em Pedagogia em 2008 e atua na educação desde 2002. Primeiramente como estagiário depois como auxiliar de educação até chegar a professor. Já fez cursos na área de artes, entre eles de teatro, desenho e dramaturgia com o intuito de melhorar sua prática de professor. Leciona há 07 anos na atual escola e, no momento, atua em uma turma de $1^{\circ}$. ano, com carga horária de 50 horas aulas por semana, 25 horas aulas com as disciplinas de Língua Portuguesa, História, Ciências e Geografia no período da manhã e à tarde mais 25 horas aulas com as oficinas de Iniciação Científica, Robótica, Experiências Matemáticas, Produção de Texto e Orientação de Estudos.

Quanto à sua percepção sobre a formação acadêmica recebida, o professor avalia que o curso de Magistério, aliado ao estágio, muito o auxiliou e influenciou em sua prática como professor.

Avalio que aprendi muito no curso de Magistério, porque podia, através do estágio vivenciar na prática, por causa dos estágios, que a gente era obrigado a fazer. Então a gente discutia um assunto pela manhã e à tarde eu podia vivenciar na prática. Muito do que eu aprendi se deve à experiência de poder acompanhar a prática de várias professoras. Na graduação tinha 80 pessoas, contra uma turma de 26 no magistério. Isso fazia muita diferença para mim.

O professor, semelhantemente à professora Capitu, afirma que não houve grandes contribuições do curso de Pedagogia para a prática da leitura literária, embora considere essa formação importante.

Nós não tínhamos uma matéria específica que falasse de literatura. O máximo que tivemos foi a leitura de um livro da Nelly Novaes Coelho, eu não me lembro o nome do livro, mas fala sobre literatura em sala de aula e tivemos indicações de bons autores brasileiros e estrangeiros para trabalhar em sala de aula. Mas uma matéria, uma formação específica para trabalhar com a formação do leitor, isso eu não tive.

A respeito de sua história como leitor literário, o professor Hamlet relembra que a habilidade de ler foi uma conquista que lhe abriu o mundo dos livros e da literatura. Ele relembrou fatos e títulos de livros, como podemos ver no trecho a seguir.

Na minha infância, nas primeiras fases entre seis e sete anos eu me lembro dos contos de Grimm. Tinha aquele livro grande, que trazia várias histórias. Ficava até meio surrado depois de passar por tantas mãos. Como eu sou de uma família grande, os livros passavam pelos irmãos, tinha rabiscos [...] e sempre era uma leitura individual. Como meus pais eram analfabetos eu não tinha quem lesse para mim. A partir do momento que eu adquiri a leitura na escola eu passei a curtir, isso na infância né? Depois o que me marcou bastante, tem um livro especial que eu digo para mim mesmo, que foi um livro que mudou a minha ideia de leitura que foi o livro [...] a gente lia os livros obrigados pela escola, que foram os livros do Marcos Rey 
SILVA, Jair Rodrigues; APARÍCIO, Ana Silvia Moço. Compartilhar literatura nos anos iniciais do ensino fundamental.

[...] fugiu um pouco o nome [...] livros do Luís Carlos Marinho. Livros de coleção infanto-juvenil, a gente lia meio que obrigado a ler, mas o livro que me marcou mesmo foi o livro de J. D. Salinger O apanhador no campo de centeio. Me marcou porque foi a primeira vez que fui à biblioteca. Mesmo sem ter a prática de ler, eu devorei o livro em três dias. Eu ia sempre à biblioteca e lia em média três livros por semana. Eu gostava dos livros de mistério, da Agatha Christie e outros que envolvessem personagens misteriosos. Eu aproveitava mais essas leituras do que as leituras que a escola nos obrigava a fazer, embora sempre tive o prazer de ler.

Quanto aos hábitos de leitura em sua vida adulta, o professor Hamlet demonstra possuir um bom repertório de leitor, não apenas de literatura, conforme relata no trecho a seguir.

\begin{abstract}
Quando eu iniciei o curso de Magistério foi na mesma época que comecei a fazer teatro, então eu comecei a ler peças de teatro. Lia comédias de Molière, peças de Sartre e depois quando fui para a Pedagogia passei a ler as indicações do curso, como os livros da Emília Ferrero, Piaget, Vygotsky [...] mas daí eu já tinha o meu gosto que era sempre o de suspense e policial e também passei a curtir muito os livros de curiosidades. Adoro pegar o Guinness Book, eu tenho em casa o Guia dos Curiosos do Marcelo Duarte. É um livro gostoso de ler e que você não precisa seguir uma sequência, pode ler o que quiser naquele dia, por exemplo. São livros que ajudam na minha prática, porque você vai adquirindo conhecimento e cultura. Hoje minhas preferências são por livros de curiosidades e livros de suspense e policial.
\end{abstract}

O professor Hamlet se considera um leitor de literatura, embora não tão assíduo como já foi um dia.

Sim, me considero um leitor. Hoje em dia eu leio semanalmente, um pouco por semana, mas já li diariamente. Agora eu estou lendo um livro de suspense, um livro bem grande de quase 1.000 páginas. Então eu leio esse livro de duas a três vezes na semana devido a outras tarefas do dia a dia da gente.

As práticas pedagógicas de ensino de leitura literária do professor Hamlet correspondem à leitura de livros em capítulos e têm uma frequência semanal. Vejamos o que ele relatou.

Eu costumo ler semanalmente para meus alunos. Isto porque eu vejo a leitura como uma atividade prazerosa e não apenas como uma obrigação. Vejo também como muito complicado um professor que não gosta de ler. Para mim é dificil analisar isso, porque eu gosto de ler. Mas imagino que deve ser muito ruim essa atividade de leitura para um professor que não gosta de ler. Deve ser uma atividade maçante para ele e seus alunos.

Ensinar a ler literatura na escola é importante para o professor Hamlet. Em sua visão, a literatura atribui qualidade e traz conhecimentos aos alunos. Para Hamlet, ler é compreender as coisas e viajar por outras épocas e sociedades. Segundo seu relato, o papel da literatura para a formação de leitores é o de agregar mais conhecimento para os alunos.

Eu acho que a literatura amplia seu mundo. Quando você lê diferentes textos, você passa a conhecer diferentes mundos. Você passa a entender diferentes sociedades e modos de pensar. Então contar um conto de Grimm, não é só um conto, mas também uma época diferente da nossa, você fala das profissões que tinham antes como o ferreiro, o moleiro, o caçador [...] e eles se perguntam: Por que não tem caçador hoje? A sociedade mudou, a sociedade evoluiu. A leitura sempre te leva a coisas novas. Ela aguça a sua 
SILVA, Jair Rodrigues; APARÍCIO, Ana Silvia Moço. Compartilhar literatura nos anos iniciais do ensino fundamental.

curiosidade, ela te ensina muita coisa. E te leva a mais conhecimento, a saber mais. A leitura muda o mundo da pessoa. Com a leitura você pode viajar para a Espanha, Grécia. Daí, se você um dia for a estes locais você vai pensar que já esteve lá, por meio da leitura é claro.

Segundo os critérios do professor Hamlet, o que torna um livro de literatura um bom livro para ser compartilhado em sala de aula é o fato de aquele livro agregar conhecimento, ou trazer um clima de suspense, de mistério e tornar o dia a dia da escola prazeroso.

Para um livro ser bom, ele precisa apresentar um desafio, ser uma porta de conhecimento. Quando você lê um livro do Marcelo Duarte por exemplo, ele traz conhecimentos muito interessantes ou como quando você lê Marcos Rey e se vê envolvido em todo o mistério da história. Você quer ler até o fim para descobrir o desfecho daquilo tudo. Um livro precisa aguçar nossa curiosidade e nos proporcionar desafio e conhecimentos. Para escolher um bom livro, é necessário pensar na turma que vai trabalhar, faixa etária e coisas assim.

Para o professor Hamlet, é essencial o papel do professor para a formação de leitores literários e, para isso, o professor deve ser um modelo de leitor. Os relatos a seguir exemplificam essa postura do professor Hamlet.

Acredito que o professor tem de ser um leitor. Se não for assim fica difícil. Como eu posso mostrar para um aluno que o livro é bom, que a leitura pode ser muito boa se eu não tenho gosto por isso? É como querer que uma criança goste de jogar bola se ela não gosta de jogar bola. Aquilo para a criança será maçante, mas se você ensinar para ela por que é legal jogar bola, talvez aquilo passe a fazer sentido para ela. Como eu disse: eu adoro ler em sala de aula, adoro ler livros em sequência com eles, eu acho que sempre traz. informações novas e é muito bom. Por isso, eu acredito que o professor deve ser um incentivador e ele mesmo mostrar, através do exemplo dele, que ler pode ser muito bom.

[...] É muito complicado quando a gente vê professores que não gostam de ler. Eu acho que a leitura é fundamental, eu acho que se o professor não tiver a curiosidade de ler fica tedioso às vezes o trabalho com as crianças. Porque muitas vezes você tem que usar referências de leitura. Você pode usar contos, materiais paradidáticos que te ajudem. Se o professor não tem essa curiosidade acaba complicando sua didática em sala de aula [...]. Quando você lê em capítulos um livro de determinado autor, como o Marcos Rey, você disponibiliza para eles outros títulos e faz uma apresentação sobre o autor, você mostra que está preocupado com a leitura deles. O professor tem que ler, se informar, pesquisar e conhecer. As crianças ficam admiradas com o conhecimento do professor [...]. O professor precisa ser um leitor. Quando eu falei para meus alunos que tinha lido o livro do Percy Jackson eles disseram: Nossa, o professor leu esse livro. Ele é adulto e leu, que legal! E isso serve de estimulante. Pois, depois disso, muitos alunos compraram os livros. Outros que não se interessavam passaram a se interessar. Quando você é um leitor e mostra isso para eles, os alunos passam a respeitar e querer mais a leitura.

Da mesma forma, para o professor Hamlet, a escolha de um bom livro para os alunos só pode acontecer se o professor também for um leitor que lê por prazer e reconhece o que é uma boa leitura.

Eu acho que faz todo o sentido, né? Para você saber o que é um bom livro você precisa conhecer, você precisa ler. Pode até ter a opinião dos outros, mas se você não tem uma concepção sua sobre o livro, às vezes até um bom livro pode se tornar um desastre em sala de aula dependendo da forma como você

Quaestio, Sorocaba, SP, v. 20, n. 1, p. 227-241, abr. 2018 
SILVA, Jair Rodrigues; APARÍCIO, Ana Silvia Moço. Compartilhar literatura nos anos iniciais do ensino fundamental.

trabalha. Nós temos escritores maravilhosos no Brasil. Para mim, ler os livros da Ana Maria Machado é um prazer, porque eu gosto da dinâmica dela. Mas, se eu não tenho interesse no assunto a leitura em voz alta mostra o meu envolvimento, mostra qual é o verdadeiro interesse da pessoa naquele assunto. A leitura tem que ser boa tanto para ele quanto para os alunos. Por isso que o planejamento tem que ter um pouco de liberdade para o professor levar livros que também lhe agradem e agradem principalmente aos alunos.

Por outro lado, para Hamlet, a escola não é um espaço que oferece uma formação para esse professor modelo de leitor.

Eu acho que não. Não há esse espaço na escola que eu atuo. Nós temos o espaço em que isso poderia ser discutido, que é o HTPC [Horário de Trabalho Pedagógico Coletivo], mas que não é utilizado, não é o que acontece.

A partir dos dados colhidos na entrevista com o professor Hamlet, é possível perceber que, ainda que não tenha passado por uma formação literária no curso de Magistério e de Pedagogia, sua formação pessoal obtida através de suas leituras e seus gostos literários influenciam-no em suas práticas pedagógicas de leitura literária. Segundo os relatos registrados na entrevista, o professor faz uso de seu repertório de leitor e de seu interesse pessoal com a literatura para trabalhar com os alunos. Para Hamlet, a escola não oportuniza um espaço de formação e trocas de experiências literárias entre os professores, o que em sua opinião dificulta o trabalho para e com os alunos.

\section{A formação literária nos âmbitos pessoal e acadêmico}

A partir dos dados das entrevistas dos professores Capitu e Hamlet, é possível perceber que a formação literária no curso de graduação quase não existiu o que pode contribuir de maneira negativa para o trabalho de formação de leitores nos anos iniciais do Ensino Fundamental. Ambos os professores não tiveram essa formação e relatam a falta dela em suas falas.

Em comum há o fato de os dois professores não terem recebido incentivo à leitura por parte dos pais, isto pelo fato dos pais serem analfabetos. Porém, no caso de Hamlet, os livros eram passados de irmão para irmão, como o livro dos contos de Grimm, ao passo que na família de Capitu não havia livros literários. 


\section{As práticas de leitura literária}

Pelo que vimos até aqui estes fatores de formação pessoal não impedem que ambos professores tenham práticas de leitura muito parecidas, que se resumem essencialmente à leitura em voz alta e na leitura em capítulos. Em outras palavras, o que explicitam sobre suas práticas é muito semelhante, independentemente de suas formações literárias. O professor Hamlet lê, segundo suas palavras, semanalmente para seus alunos, o que nos leva a compreender que não o faz diariamente, assim como a professora Capitu que lê uma ou duas vezes na semana.

Um fator que influencia suas práticas de leitura literária parece ser as demandas da instituição escolar como frisa Capitu que gostaria de ler mais, mas não há tempo e para Hamlet, um fator também se dá pela falta de oportunidade de formação para os professores e trocas sobre práticas literárias nos encontros de formação do HTPC (Horário de Trabalho Pedagógico Coletivo) da escola onde atuam.

\section{A influência da formação literária nas práticas de leitura}

O que podemos concluir acerca da fala dos professores é que ambos reconhecem o valor da literatura e sua importância para a formação de leitores. Mas, devido a fatores como, falta de incentivo e não haver formação continuada a esse respeito nos espaços de formação, como o HTPC, reduzem suas práticas literárias a leituras em voz alta realizadas semanalmente. Outro fator importante é que suas formações pessoais com a literatura não parecem influenciá-los a práticas que saiam do que é comum, do que já é estabelecido e visto como uma prática literária escolarizada (SOARES, 2011).

Seguramente as práticas relatadas pelos professores não corroboram com o que acreditamos ser o compartilhar literatura. Diante da fala dos professores e suas formações literárias fica evidente a urgência de se pensar na formação do professor para compartilhar literatura na escola.

Como ressaltam Dalvi, Rezende e Jover-Faleiros (2013), ao contrário do ensino de língua que vem se renovando ao longo das últimas décadas, a literatura na escola ainda resiste às mudanças, ficando em segundo plano na formação de nossos estudantes. 


\section{Considerações finais}

Compartilhar literatura nas salas de aula dos anos iniciais de ensino fundamental poderá se constituir numa atividade significativa e enriquecedora para a formação de professores e de alunos leitores de literatura. Mais do que simplesmente ler textos literários, compartilhar literatura entre alunos e professores, oportuniza a participação, com vistas a formar uma comunidade de leitores.

Compartilhar significa ir ao outro, participar, dividir momentos de fruição que a experiência literária pode proporcionar aos envolvidos. Compartilhar pressupõe envolvimento e comunhão dentro do processo de ensino aprendizado.

A escola, ao invés de impor e cobrar leituras dos alunos o que torna a leitura literária uma tarefa burocratizada e árdua, deveria se converter num lugar em que o texto literário oral ou escrito, clássico ou popular seja uma viva experiência artística e como tal deixe suas marcas na história de vida das pessoas. Somente essa escola pode formar leitores maduros, que leiam criticamente, e por hábito, além dos muros da escola.

Nossa esperança é como a de Paulo Freire (1996): a de que professores e alunos juntos podem aprender, ensinar e produzir. Até porque acreditamos, também à semelhança de Freire, que a mudança é possível.

Para vislumbrar este horizonte, necessitamos de melhor formação para nós professores, tanto no curso de Pedagogia, quanto na formação continuada de docentes para atuar nos anos iniciais do Ensino Fundamental. Uma formação na perspectiva de compartilhar literatura como uma experiência significativa para docente e alunos.

E nessa relação de esperança, crença e luta a literatura é uma flor bonita que brota a cada dia de trabalho, nos emocionando, fazendo rir, chorar, nos metendo medo e nos lembrando a todo o tempo de nossa humanidade.

\section{Referências}

BENJAMIN, Walter. O Narrador. Considerações sobre a obra de Nikolai Leskov. In: BENJAMIN, Walter. Magia e técnica, arte e política: ensaios sobre literatura e história da cultura. 7. ed. São Paulo: Brasiliense, 1994.

CUNHA, Antônio Geraldo da Cunha. Dicionário etimológico Nova Fronteira da língua portuguesa. Rio de Janeiro: Nova Fronteira, 1997. 
DALVI, Maria Amélia; REZENDE, Neide Luzia de; JOVER-FALEIROS, Rita. (Org.).

Leitura de literatura na escola. São Paulo: Parábola, 2013.

DICIONÁRIO Michaelis. Disponível em: <http://michaelis.uol.com.br/busca?id=xWkG>. Acesso em: 9 jan. 2017.

FREIRE, Paulo. Pedagogia da autonomia. São Paulo: Paz e Terra, 1996.

MACHADO, Regina. Acordais fundamentos teóricos-poéticos da arte de contar histórias. São Paulo: DCL, 2004.

SOARES, Magda. A escolarização da literatura infantil e juvenil. In: EVANGELISTA, Aracy Alves Martins; BRANDÃO, Heliana Maria Brina; MACHADO, Maria Zélia Versiani. (Org.). Escolarização da leitura literária. 2. ed. Belo Horizonte: Autêntica, 2011.

TODOROV, Tzvetan. A literatura em perigo. Rio de Janeiro: DIFEL, 2010.

\author{
Jair Rodrigues Silva \\ Universidade Municipal de São Caetano do Sul - USCS | Mestre \\ em Educação pelo Programa de Mestrado Profissional em \\ Educação \\ São Caetano do Sul | SP | Brasil. \\ Contato: jair.rodrigues@yahoo.com.br \\ ORCID 0000-0002-5979-1017 \\ Ana Silvia Moço Aparício \\ Universidade Municipal de São Caetano do Sul - USCS | Programa \\ de Mestrado Profissional em Educação \\ São Caetano do Sul | SP | Brasil. Contato: anaparicio@uol.com.br \\ ORCID 0000-0001-6725-5372
}

Artigo recebido em: 7 out. 2017 e aprovado em: 21 jan. 2018. 